\title{
Ten-Year-Trend of HIV Prevalence among Pregnant Women in Benin
}

\author{
Aguemon Badirou ${ }^{1, *}$, Sossa Jérôme Charles ${ }^{2}$, Sopoh Ghislain Emmanuel ${ }^{3}$, Damien Barikissou Georgia ${ }^{1}$, \\ Saizonou Jacques ${ }^{4}$, Houeto David ${ }^{5}$, Gado Thalouth A A ${ }^{1}$, Ouendo Edgard Marius ${ }^{4}$ \\ ${ }^{1}$ Department of Public Health, Faculty of Health Sciences, University of Abomey-Calavi, Benin \\ ${ }^{2}$ Department of Health Promotion, Regional Institute of Public Health, University of Abomey-Calavi, Benin \\ ${ }^{3}$ Department of Health and Environment, Regional Institute of Public Health, University of Abomey-Calavi, Benin \\ ${ }^{4}$ Department of Policy and Health Systems, Regional Institute of Public Health, Benin \\ ${ }^{5}$ National High School of Epidemiological Surveillance, University De Parakou, Benin
}

Copyright $\bigcirc 2018$ by authors, all rights reserved. Authors agree that this article remains permanently open access under the terms of the Creative Commons Attribution License 4.0 International License

\begin{abstract}
Background: HIV infection for children is mainly due to mother-to-child transmission (MTCT) that can occur during pregnancy, childbirth and breastfeeding. In Benin, the residual rate of HIV transmission from mother to child remained high. The objective of the study was to describe a ten-year-trend of HIV prevalence in pregnant women in Benin. Methods: A retrospective study was carried out from 2006 to 2015 across the country and consisted in reviewing the reports of the annual surveys of HIV infection among pregnant women. Chi square test was used to assess the trend over time of HIV prevalence among pregnant women. Equations of regression lines of HIV prevalence trend graphs were estimated to determine the direction of the trend. Results: A total of 138,319 pregnant women participated in the annual HIV surveys from 2006 to 2015. The prevalence of HIV infection from 2006 to 2015 for pregnant women decreased significantly in the group of women aged 20-29 years, in the group of craftswomen and in the group of women with their first pregnancy. In contrary, the prevalence of HIV increased significantly for women with at least four past pregnancies and those writing in local language. Conclusion: The National AIDS control program may take these results into account by maintaining the epidemiological surveillance in $\mathrm{HIV}$, and reinforce interventions for the vulnerable groups where the prevalence increased.
\end{abstract}

Keywords HIV, Pregnancy, Socio-demographic Characteristics, Benin

\section{Introduction}

The HIV epidemic is a public health problem, particularly in sub-Saharan Africa [1,2]. HIV infection for children is mainly due to mother-to-child transmission (MTCT) of HIV that can occur during pregnancy, childbirth and breastfeeding [3-5]. Given the many strategies of combating this pandemic, this form of transmission is unacceptable and even intolerable. In Africa the most HIV-infected people are teenagers and young women, reflecting the feminization of HIV infection [6].

In Benin, several national strategic plans to control mother-to-child transmission of HIV have been developed and implemented. The first strategic plan for the elimination of mother-to-child transmission covered the period from 2012 to 2015 and a second plan extends from 2015 to 2020 [7]. Nevertheless, the residual rate of HIV transmission from mother to child remained high $(7.62 \%)$ in 2014 [8]. In 2012, the Benin Demographic and Health Survey reported the HIV prevalence among the general population of $1.2 \%$ with a feminization of the epidemic: $1.4 \%$ among women compared to $1.0 \%$ among men [9]. These observations assumed the possible increase in the number of HIV-positive pregnant women. The objective of this study was to analyze the trend of HIV infection prevalence among pregnant women in Benin from 2006 to 2015.

\section{Materials and Methods}

\subsection{Setting}

The study was conducted in Benin, whose population was estimated by the last census in 2013 at $10,008,749$ inhabitants. Women represented $51.2 \%$ of the population. The natural growth rate was estimated at $3.52 \%$ per year. Benin's health system has a pyramidal structure of three levels: central, intermediate and peripheral. The structure 
in charge of the fight against HIV and AIDS is the National Committee for the Fight against AIDS which operational entity is the National AIDS Control Program (PNLS) with regional offices called "information center, foresight and Advisory Council on HIV and AIDS" (CIPEC). HIV test for pregnant women during prenatal consultations (ANC) is ensured in health facilities.

\subsection{Study Design}

This was a retrospective study that used the results of annual HIV surveys among pregnant women from 2006 to 2015. The study was conducted from June $1^{\text {st }}$ to December $31^{\text {st }}, 2016$.

Annual HIV surveys involved pregnant women attending selected maternal health centers which are sentinel sites for tracking HIV infection.

\subsection{Sampling}

\section{Selection of Antenatal Care Services for Annual HIV Surveys}

For the purpose of annual surveys, PNLS selected 65 sentinel sites for HIV survey among pregnant women. These sites covering urban and rural areas and spreading across 30 municipalities in the 12 regions of Benin, were selected according to criteria of geographical accessibility and attendance in antenatal care service.

\section{Pregnant Women Selected for Annual HIV Surveys}

The sample of annual HIV surveys from 2006 to 2015 consisted of pregnant women admitted to sentinel sites during the period of the annual survey.

\subsection{Inclusion and Exclusion Criteria in Annual HIV Surveys in Pregnant Women}

Pregnant women who attended first sentinel antenatal care service for ongoing pregnancy were included in annual HIV survey. Pregnant women who were already registered in the antenatal care center for the pregnancy in progress before the start of annual HIV survey and those who did not give their informed consent were not included in the annual HIV surveys. Pregnant women whose blood samples were inadequate for HIV testing were excluded from the study.

\subsection{Data Collection Processes in Annual HIV Surveys for Pregnant Women}

In Benin, annual HIV survey in pregnant women is divided into two parts. The first consists of a collection of data by individual interview and the second into a blood sample collection for screening.

HIV has been screened by strategy II recommended by WHO and UNAIDS [10] for national prevalence of less than $10 \%$. This strategy consists in making a first sensitive test, then HIV-positive blood samples are confirmed by a second specific and discriminating test. The first test used is Determine ${ }^{\circledR}$. The confirmatory test used is a sensitive, specific and discriminating rapid test ImmunoComb II HIV-1 / HIV-2 Bi Spot. For quality assurance purposes of the laboratory tests, all HIV-positive samples, indeterminate samples and $2 \%$ of the negative ones are sent to the National Reference Laboratory of the PNLS for quality control.

\subsection{Variables of the Study on HIV Prevalence Trend for Pregnant Women from 2006 to 2015}

The dependent variable was the HIV status of pregnant women. It is obtained from the biological test performed on a blood sample.

The independent variables were socio-demographic variables: age of pregnant women, marital status, level of education, number of pregnancy and occupation.

\subsection{Data Collection Procedures for Study on HIV Prevalence Trend for Pregnant Women from 2006 to 2015}

Data was collected from documentary review. The ten annual HIV survey reports (2006-2015) for pregnant women were reviewed.

Data analysis

Data were analyzed with the STATA 12 software. The Chi-square test for trend was used to assess the trend over time of HIV prevalence among pregnant women. The Excel 2013 software was used to estimate the equation of the regression lines for bar graphs of annual HIV prevalence in pregnant women. The significance level was fixed at $\mathrm{p}<0.05$.

\subsection{Ethical Considerations}

An authorization to use data from annual HIV survey reports among pregnant women in Benin from 2006 to 2015 was obtained from the National AIDS Control Program (PNLS) Coordinator. For annual surveys, oral consent was already obtained from each pregnant woman during each survey. This consent stipulated that patients were free to participate or not in the investigation without any prejudice. HIV testing and data of survey were anonymous.

\section{Results}

\subsection{Characteristics of Participants}

A total of 138,319 pregnant women participated in the 
annual HIV surveys from 2006 to 2015, women aged between 20 and 24 (29.49\%) and from 25 to 29 (30.58\%) were the most represented. Among pregnant women, $61 \%$, $17.12 \%$ and $14.59 \%$ were respectively cohabiting, married or single. Pregnant women who never went to school $(43.3 \%)$ predominated compared to those with a primary education (20.7\%) and "secondary or high education" (18.1\%). Of the pregnant women, $45.2 \%$ were housewives and $35 \%$ lived in urban areas.

\subsection{Ten-Year-Trend of HIV Prevalence Infection among Pregnant Women by Age}

Table 1 below describes HIV prevalence trend among pregnant women by age. HIV prevalence among pregnant women significantly fluctuated among pregnant women aged 20-24 years $(p=0.001)$ and $25-29$ years $(p=0.007)$, (Table1). But the general trend showed the decrease of HIV prevalence from 2006 to 2015 in the both age groups. The estimated equation of regression lines of HIV prevalence graphs in pregnant women from 20 to 24 showed a decreasing trend: $y=-0.0642 x+2.0133\left(R^{2}=0.4034\right)$, (Figure1). The same trend was observed in pregnant women aged 25 to 29 years: $\mathrm{y}=-0.0309 \mathrm{x}+2.16\left(\mathrm{R}^{2}=\right.$ 0.0686), (Figure2).

$$
\mathrm{y}=-3.0909 \mathrm{x}+216
$$$$
\mathrm{R}^{2}=0.0686
$$

Table1. HIV prevalence trend among pregnant women by age in Benin from 2006 to 2015

\begin{tabular}{|c|c|c|c|c|c|c|c|c|c|c|c|}
\hline Ages & \multicolumn{9}{|c|}{ HIV prevalence for pregnant women } & \multicolumn{1}{|c|}{ p } \\
\hline & $\mathbf{2 0 0 6}$ & $\mathbf{2 0 0 7}$ & $\mathbf{2 0 0 8}$ & $\mathbf{2 0 0 9}$ & $\mathbf{2 0 1 0}$ & $\mathbf{2 0 1 1}$ & $\mathbf{2 0 1 2}$ & $\mathbf{2 0 1 3}$ & $\mathbf{2 0 1 4}$ & $\mathbf{2 0 1 5}$ & \\
\hline $\mathbf{1 5 - 1 9}$ & 0.8 & 0.9 & 0.7 & 1.8 & 0.7 & 1 & 0.4 & 0.5 & 0.6 & 0.9 & 0.051 \\
\hline $\mathbf{2 0 - 2 4}$ & 1.7 & 2.1 & 2.3 & 1.6 & 1.6 & 1.3 & 1.5 & 1.5 & 1.5 & 1.5 & 0.001 \\
\hline $\mathbf{2 5 - 2 9}$ & 1.6 & 2.3 & 2.5 & 2.5 & 1.5 & 2.1 & 1.8 & 1.9 & 1.7 & 2 & 0.007 \\
\hline $\mathbf{3 0 - 3 4}$ & 1.6 & 1.7 & 1.9 & 2.7 & 2.3 & 2.7 & 2.5 & 2.3 & 1.6 & 2.1 & 0.998 \\
\hline $\mathbf{3 5 - 3 9}$ & 1.9 & 2.1 & 2.3 & 2.4 & 2.2 & 2.1 & 2.3 & 3 & 2.1 & 2.1 & 0.807 \\
\hline $\mathbf{4 0 - 4 4}$ & 1.7 & 0.6 & 3.4 & 1.3 & 2.5 & 1.2 & 2.2 & 0.8 & 1.7 & 0.3 & 0.280 \\
\hline
\end{tabular}

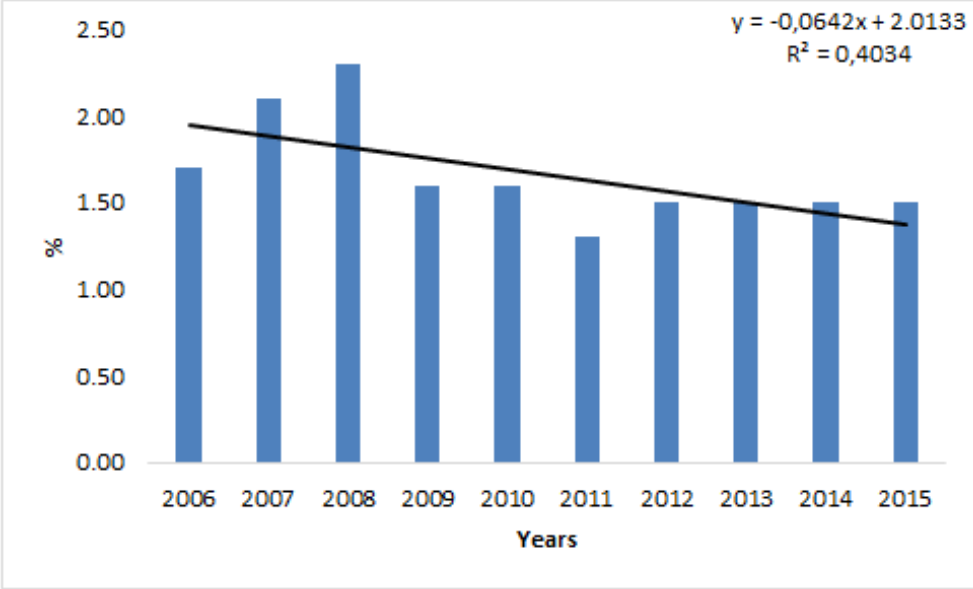

Figure 1. HIV prevalence trend among pregnant women aged from 20 to 24 years old in Benin from 2006 to 2015.

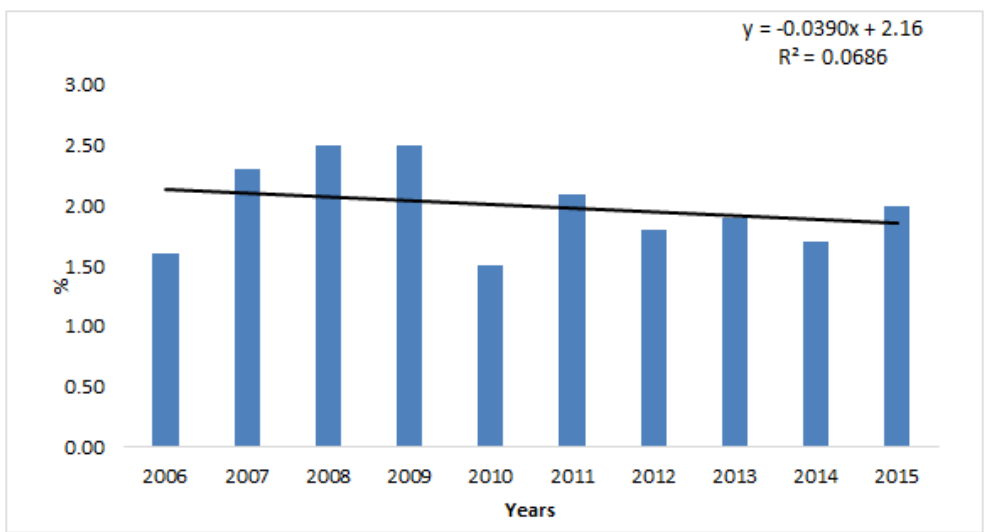

Figure 2. HIV prevalence trend among pregnant women aged from 25 to 29 years old in Benin from 2006 to 2015. 


\subsection{Ten-Year-Trend of HIV Prevalence among Pregnant Women by Marital Status}

The prevalence rates of HIV infection among pregnant women were constant irrespective of marital status (Table 2).

Table 2. HIV prevalence trend among pregnant women by marital status in Benin from 2006 to 2015

\begin{tabular}{|c|c|c|c|c|c|c|c|c|c|c|c|}
\hline Marital status & \multicolumn{10}{|c|}{ HIV prevalence in pregnant women } & p \\
\hline & $\mathbf{2 0 0 6}$ & $\mathbf{2 0 0 7}$ & $\mathbf{2 0 0 8}$ & $\mathbf{2 0 0 9}$ & $\mathbf{2 0 1 0}$ & $\mathbf{2 0 1 1}$ & $\mathbf{2 0 1 2}$ & $\mathbf{2 0 1 3}$ & $\mathbf{2 0 1 4}$ & $\mathbf{2 0 1 5}$ & \\
\hline Single & 2.1 & 1.9 & 2.3 & 2.5 & 1.6 & 1.9 & 2.6 & 1.5 & 2 & 2.4 & 0.166 \\
\hline Married & 2.3 & 2 & 2.1 & 2.2 & 1.3 & 2.5 & 1.7 & 1.9 & 1.7 & 1.5 & 0.698 \\
\hline Cohabiting & 0 & 0 & 5 & 2.1 & 3.4 & 3.9 & 5 & 4.4 & 3.6 & 2.3 & 0.774 \\
\hline
\end{tabular}

\subsection{Ten-Year-Trend of HIV Prevalence among Pregnant Women by Occupation}

Table 3 below shows that HIV prevalence trend in pregnant women has a significantly fluctuated in craftswomen $(\mathrm{p}<0.0001)$. The estimated equation of regression lines of HIV prevalence trend graphs in pregnant craftswomen showed a decreasing trend: $y=-0.2473 x+4.08\left(R^{2}=0.6521\right)$, (Figure3).

Table 3. HIV prevalence trend among pregnant women by occupation in Benin from 2006 to 2015

\begin{tabular}{|c|c|c|c|c|c|c|c|c|c|c|c|}
\hline Profession & \multicolumn{9}{|c|}{ HIV prevalence for pregnant women } & p \\
\hline & $\mathbf{2 0 0 6}$ & $\mathbf{2 0 0 7}$ & $\mathbf{2 0 0 8}$ & $\mathbf{2 0 0 9}$ & $\mathbf{2 0 1 0}$ & $\mathbf{2 0 1 1}$ & $\mathbf{2 0 1 2}$ & $\mathbf{2 0 1 3}$ & $\mathbf{2 0 1 4}$ & $\mathbf{2 0 1 5}$ & \\
\hline Traders & 2.9 & 2.9 & 3.1 & 2.8 & 2.2 & 3.1 & 2.7 & 2.9 & 2.2 & 2.9 & 0.370 \\
\hline House women & 1.8 & 1.2 & 1.3 & 1.9 & 1.8 & 1.3 & 1.4 & 1.6 & 1.3 & 1.5 & 0.978 \\
\hline Farmers & 0.6 & 1.8 & 1.6 & 1.7 & 0.6 & 0.6 & 1.9 & 1.6 & 1 & 1.7 & 0.684 \\
\hline Pupil/students & 1.9 & 0.9 & 1.2 & 1 & 0.8 & 2.2 & 0.5 & 0.8 & 1 & 1.2 & 0.903 \\
\hline Trainees & 0.8 & 2.5 & 1.2 & 2.4 & 1.4 & 1 & 1.5 & 1.7 & 1.6 & 1.3 & 0.324 \\
\hline Craftswomen & 4.9 & 2.9 & 3.4 & 2.4 & 2.4 & 2.8 & 2.8 & 1.8 & 2.1 & 1.7 & $<0.0001$ \\
\hline Government staff & 7.8 & 1.7 & 2.1 & 2.9 & 0.6 & 1.2 & 1.6 & 1 & 2.5 & 1.2 & 0.491 \\
\hline Unemployed & 2.7 & 0 & 0.2 & 7.4 & 2.5 & 0 & 2.7 & 1.7 & - & - & 0.548 \\
\hline
\end{tabular}

(-) Data unavailable

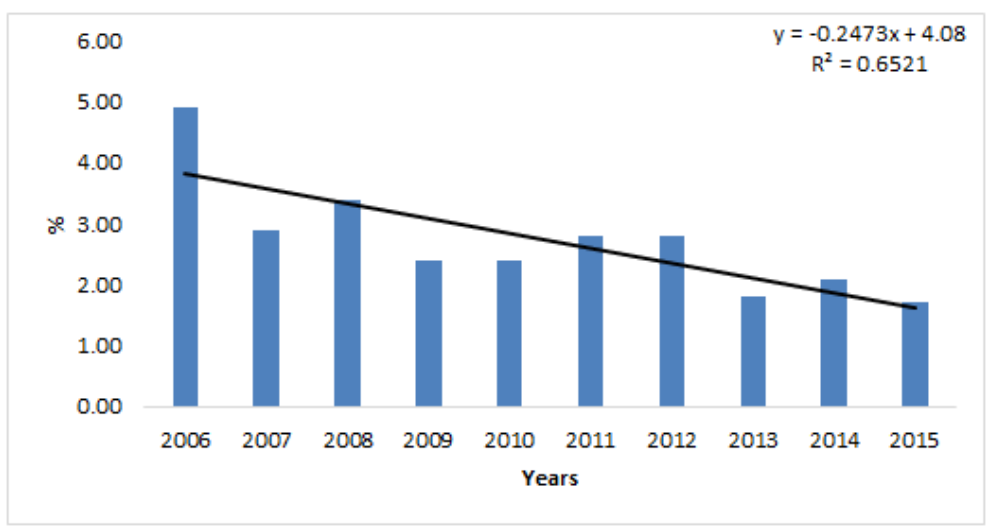

Figure 3. HIV prevalence trend among craftswomen in pregnancy in Benin from 2006 to 2015

\subsection{Ten-Year-Trend of HIV Prevalence among Pregnant Women according to Their Spouses' Occupations}

Table 4 below reveals that HIV prevalence among pregnant women according to the occupation of the pregnant spouses had a constant trend. 
Table 4. HIV prevalence trend among pregnant women according to the occupation of their spouse in Benin from 2006 to 2015

\begin{tabular}{|c|c|c|c|c|c|c|c|c|c|c|c|}
\hline Women' spouses occupation & \multicolumn{9}{|c|}{ HIV prevalence for pregnant women } & p \\
\hline & $\mathbf{2 0 0 6}$ & $\mathbf{2 0 0 7}$ & $\mathbf{2 0 0 8}$ & $\mathbf{2 0 0 9}$ & $\mathbf{2 0 1 0}$ & $\mathbf{2 0 1 1}$ & $\mathbf{2 0 1 2}$ & $\mathbf{2 0 1 3}$ & $\mathbf{2 0 1 4}$ & $\mathbf{2 0 1 5}$ & \\
\hline Trader & 2.7 & 2.1 & - & 1.8 & - & 2.2 & 2.3 & 2.9 & 2.1 & 2.3 & 0.548 \\
\hline Farmer & 0.5 & 1 & - & 1.3 & - & 1 & 1.1 & 1.2 & 0.9 & 1.4 & 0.490 \\
\hline Pupil or Student & 2.8 & 1.2 & - & 2.6 & - & 1.8 & 0.8 & 0.6 & 1.2 & 1.4 & 0.192 \\
\hline Craftsmen & 4.2 & 1 & - & 3 & - & 2.5 & 2.3 & 2.8 & 2.3 & 1.6 & 0.887 \\
\hline Artists & 3.1 & 2.5 & - & 1.3 & - & 3.3 & 2.6 & 1.7 & 2.3 & 3.3 & 0.534 \\
\hline Government staff & 8.6 & 1.9 & - & 2.4 & - & 1.9 & 2.2 & 1.5 & 1.7 & 1.8 & 0.229 \\
\hline Drivers & - & 2.9 & - & 2.9 & - & 2.4 & 2.8 & 2 & 2.2 & 2.9 & 0.473 \\
\hline
\end{tabular}

(-) Data unavailable

\subsection{Ten-Year-Trend of HIV Prevalence among Pregnant Women by Level of Education}

Table 5 below showed that HIV prevalence among pregnant women has a significantly from 2006 to 2015 in the groups of no schooling women $(\mathrm{p}<0.0001)$. The estimated equation of regression lines of HIV prevalence trend graphs in pregnant women trained in writing in local language showed an increasing trend: $y=0.3012 x+0.0733\left(R^{2}=0.3437\right)$, (Figure4).

Table 5. HIV prevalence trend among pregnant women by level of education in Benin from 2006 to 2015

\begin{tabular}{|c|c|c|c|c|c|c|c|c|c|c|c|}
\hline Education & \multicolumn{9}{|c|}{ HIV prevalence for pregnant women } & p \\
\hline & $\mathbf{2 0 0 6}$ & $\mathbf{2 0 0 7}$ & $\mathbf{2 0 0 8}$ & $\mathbf{2 0 0 9}$ & $\mathbf{2 0 1 0}$ & $\mathbf{2 0 1 1}$ & $\mathbf{2 0 1 2}$ & $\mathbf{2 0 1 3}$ & $\mathbf{2 0 1 4}$ & $\mathbf{2 0 1 5}$ & \\
\hline No schooling & 0 & 0 & 2.7 & 2.8 & 1.3 & 0 & 0.4 & 2.8 & 4 & 3.3 & $<0.0001$ \\
\hline Primary & 2.4 & 2.8 & 2.8 & 2.4 & 2.3 & 2.5 & 2.3 & 2.2 & 2.1 & 2.6 & 0.152 \\
\hline$\geq$ Secondary & 2.3 & 1.9 & 3.8 & 5.3 & 3.4 & 3.5 & 2.3 & 2.8 & 3.5 & 2.6 & 0.114 \\
\hline
\end{tabular}

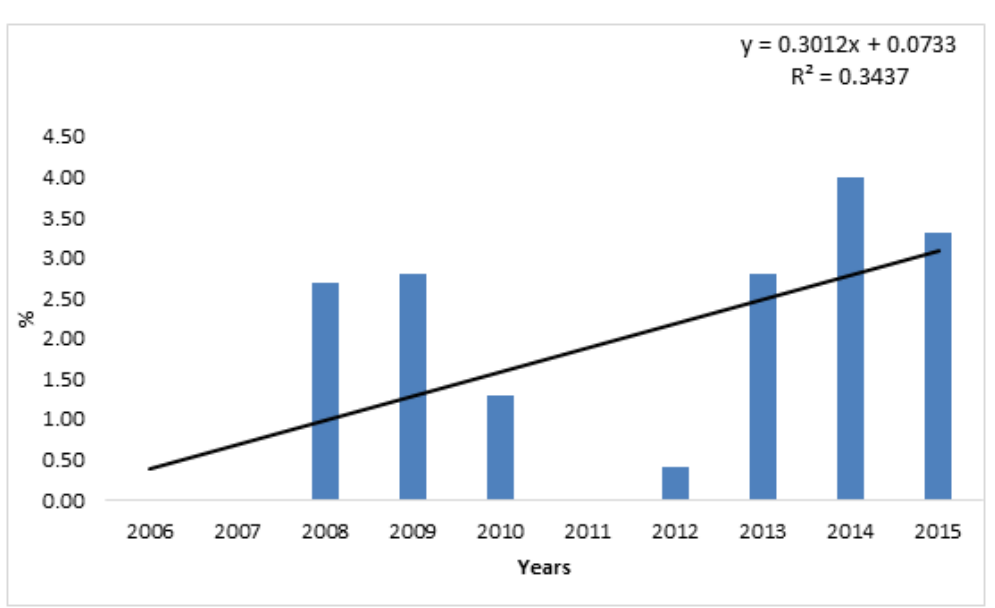

Figure 4. HIV prevalence trend among pregnant and no schooling women in Benin from 2006 to 2015.

\subsection{Ten-Year-Trend of HIV Prevalence for Pregnant Women by Number of Pregnancies}

Table 6 below illustrates that HIV prevalence for pregnant women has a significantly varied according to the years in women who experienced the first pregnancy $(p=0.008)$ and those who experienced more than five pregnancies $(p<0.0001)$. The estimated equation of regression lines of HIV prevalence trend graphs in women who experienced the first pregnancy shows a decreasing trend $\left(y=-0.0345 x+1.34\left(R^{2}=0.024\right)\right.$, (Figure5), and an increasing trend in those who experienced more than five pregnancies $\left(y=0.2679 x+0.8267\left(R^{2}=0.3159\right)\right.$, (Figure6). 
Table 6. HIV prevalence trend among pregnant women by number of pregnancies in Benin from 2006 to 2015

\begin{tabular}{|c|c|c|c|c|c|c|c|c|c|c|c|}
\hline Number of pregnancy & \multicolumn{9}{|c|}{ HIV prevalence for pregnant women } & \multicolumn{2}{c|}{ p } \\
\hline & $\mathbf{2 0 0 6}$ & $\mathbf{2 0 0 7}$ & $\mathbf{2 0 0 8}$ & $\mathbf{2 0 0 9}$ & $\mathbf{2 0 1 0}$ & $\mathbf{2 0 1 1}$ & $\mathbf{2 0 1 2}$ & $\mathbf{2 0 1 3}$ & $\mathbf{2 0 1 4}$ & $\mathbf{2 0 1 5}$ & \\
\hline $\mathbf{1}$ & 1.8 & 1.9 & - & 1.8 & - & 1.3 & 1.3 & 1.1 & 1.1 & 1.2 & 0.008 \\
\hline $\mathbf{2}$ to $\mathbf{4}$ & 2.2 & 2.2 & - & 2.4 & - & 2.3 & 2.1 & 2.1 & 1.9 & 2.2 & 0.242 \\
\hline $\mathbf{2 5}$ & 2.6 & 2.2 & - & 1.6 & - & 2.1 & 3.7 & 4.1 & 3.1 & 3.6 & $<0.0001$ \\
\hline
\end{tabular}

(-) Data unavailable

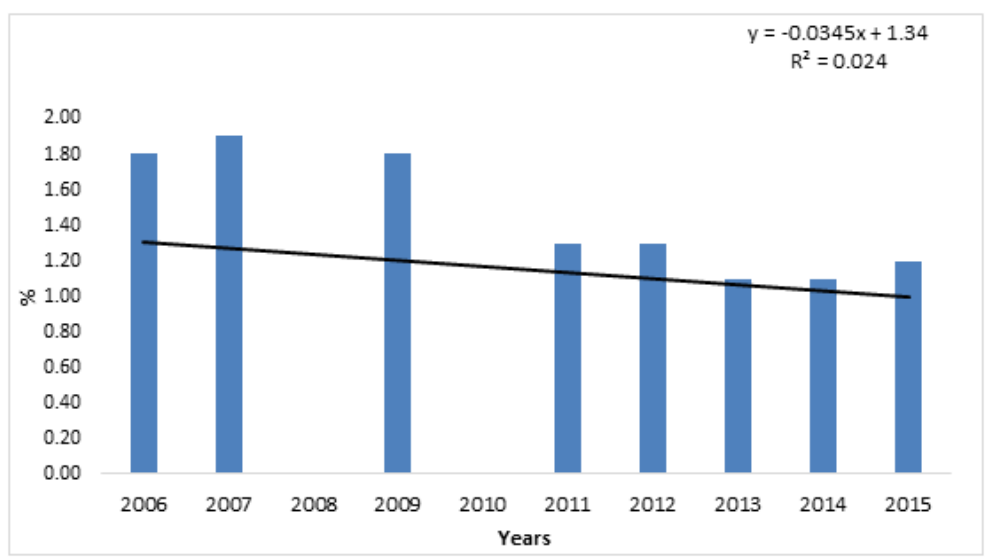

Figure 5. HIV prevalence trend among pregnant women in first pregnancy group in Benin from 2006 to 2015

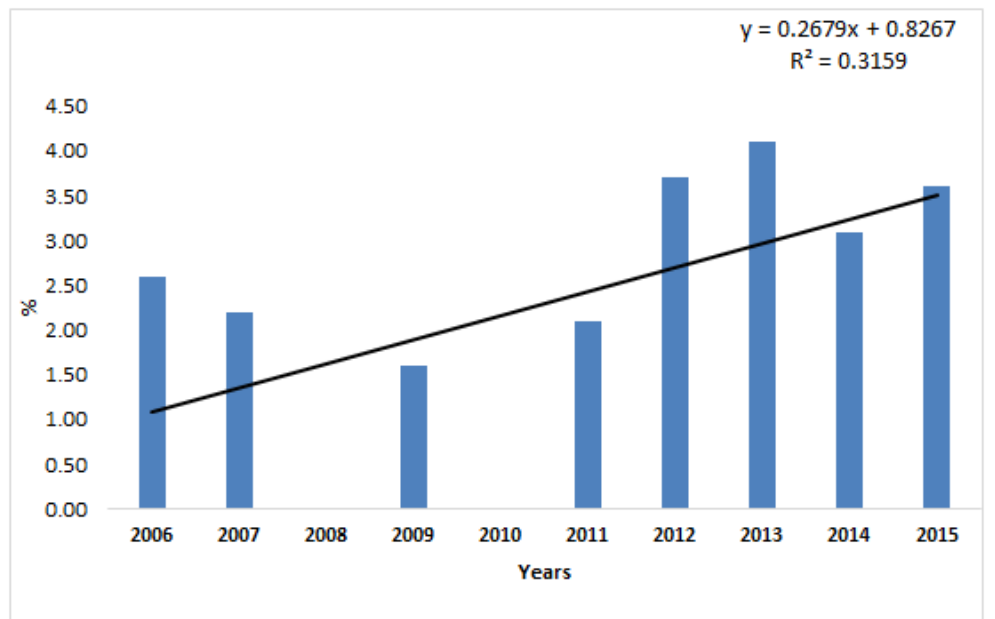

Figure 6. HIV prevalence trend among pregnant women in more than five pregnancies group in Benin from 2006 to 2015

\section{Discussion and Recommendation}

This study examined the trend of HIV prevalence among pregnant women in Benin over the past ten years (2006-5015). The trend of HIV prevalence among pregnant women was significantly decreasing among women aged 20-29, craftswomen and women with first pregnancy, while it was significantly increasing among no schooling pregnant women and women who experienced more than five pregnancies. These results are similar to those reported by Kwiek et al. [11] in Malawi, which found as socio-demographic factors associated with the prevalence of HIV infection among pregnant women: age, number of pregnancies, marital status and occupation of pregnant women. A systematic review to assess whether educational status is associated with HIV-1 infection conducted in developing countries showed that longer duration of schooling was strongly protective against HIV infection in Africa in rural areas [12]. Ukaire et al. [13] in Nigeria in 2014 observed that education was associated with HIV infection among pregnant women. Uneducated women, including the illiterate, are more vulnerable to HIV; this has been confirmed by Michelo et al. [14] in Zambia. A study conducted by UNAIDS in Uganda found that the prevalence of HIV infection among women with a high school education was low [15]. Then, schooling appears to be a protective factor against HIV infection, as observed in this study: HIV prevalence trend is not statistically significant among pregnant women with secondary or high education. 
Access to education is an essential tool with which women and girls can protect themselves against HIV. School attendance increases the chance that girls will be able to access information and build the confidence and skills necessary to protect themselves from HIV [7]. This could be explained by the fact that schooling makes it possible to acquire a global knowledge on HIV and AIDS, namely the modes of transmission and the means of prevention such as the use of the condom which reduces considerably (20 times) the risk of HIV infection [16]. So, girls' non-schooling and dropping out of school may contribute to increasing HIV prevalence among women.

Young people are vulnerable to HIV infection due to active sexual activities in this period. The statistically significant decreased trend observed change found in the age group of 20 to 29 could be explained by the interventions of PNLS against HIV in Benin. Indeed, several health interventions against HIV targeting youth were implemented by PNLS [6]. Similar results have already been showed by a study which measured HIV prevalence trends among all women aged 15-49 years and currently pregnant women between surveys conducted from 2003 to 2008 and 2009 to 2012 . This study found that HIV prevalence decreased significantly among women aged 15-24 years while increasing significantly among women $35-49$ years, who represented $29 \%$ of pregnant women [17].

Reducing number of pregnancies was associated with decreasing ten-year-trend of HIV prevalence in pregnant women. It is well established that girls' schooling has a positive influence on family planning, which plays a significant role in reducing number of pregnancy. Among the most basic health services for women and girls are sexual and reproductive health which include: family planning, contraception, which are essential to enable women to protect themselves from HIV [7].

Increasing number of pregnancy was associated with increased HIV prevalence trend over times. Indeed, increased number of pregnancies means long sexual experience which increases the risk of HIV infection [18].

A study conducted by the South African Department of Education in 2006 reported an economic barrier that was a drag on girls' schooling [19]. This factor would probably lead to school drop-out, especially for girls, which keeps girls out of school. Duflo et al. [20] in Kenya in 2006 showed that the reduction of economic barriers positively impacted on the one hand school dropout and on the other hand on number of pregnancies. Pettifor et al. [21] in South Africa showed that reducing these economic barriers leads to girls' enrollment and reduced risk of HIV infection. This may explain the statistically significant trend observed among economically vulnerable craftswomen [16], most of whom have either dropped out of school or are out of school.

Given the results of this study, it is necessary to maintain awareness and prevention efforts where the HIV trend is constant or in progression, to strengthen HIV action in groups where the trend is on the rise. The PNLS should analyze the evolution of the prevalence of HIV infection in pregnant women through a long period in order to identify the gap of intervention effect and adjusted where necessary.

\section{Conclusions}

Ten-year-trend of HIV infection prevalence among pregnant women fluctuated in certain social groups between 2006 and 2015. The National AIDS control program may take these results into account by maintain the epidemiological surveillance in HIV, and reinforce interventions in the vulnerable groups where the prevalence increased.

\section{Conflicts of Interest}

The authors state that there is no conflict of interest for this study.

\section{REFERENCES}

[1] Organisation Mondiale de la Santé. Dix faits sur le VIH/sida. Disponible sur : http://www.who.int/features/factfiles/hiv/fr/. Consulté le $02 / 02 / 2018$

[2] ONUSIDA. Rapport ONUSIDA sur l'épidémie mondiale de sida 2014. 299p

[3] R. Soeiro, A. Rubinstein, W.K. Rashbaum, W.D. Lyman. Maternofetal Transmission of AIDS: Frequency of Human Immunodeficiency Virus Type 1 Nucleic Acid Sequences in Human Fetal DNA. J Infect Dis. 1992;166(4):699-703.

[4] P. Gaillard, C. Verhofstede, F. Mwanyumba, P. Claeys, V. Chohan, K. Mandaliya et al. Exposure to HIV-1 during delivery and mother-to-child transmission. AIDS. 2000;14(15):2341-8.

[5] G. Scarlatti. Mother-to-child transmission of HIV-1: advances and controversies of the twentieth centuries. AIDS Rev. 2004;6(2):67-78.

[6] GBC Health. Overview of the feminization of HIV/AIDS in sub-Saharan Africa. Available on http://www.gbchealth.org/system/documents/category_1/36 4/Feminization_HIV_Sub Saharan_Africa Issue Brief.pdf ?1345233500. Accessed on 02 January 2018.

[7] République du Benin. Plan national d'élimination de la transmission du VIH de la mère à l'enfant (2012-2015). PNLS. Cotonou, 2012, 85p

[8] C.J. Sossa, M. Agonnoudé, A.I. Bah-Chabi, J.Y. Daho, M. Bachabi, A. de Souza et al. Evaluation de la transmission de l'infection à VIH de la mère à l'enfant au Bénin en 2014. Cahiers du CBRST, Cotonou (Bénin). 2015;8(4):627-645. 
[9] Institut Nationale de la Statistique et de l'Analyse Economique (INSAE). Enquête démographique et de santé (EDSB-IV) 2011-2012. Cotonou: INSAE. 2013. 573p.

[10] WHO. Directives pour l'évaluation des techniques de dépistage du VIH en Afrique, available on http://www.who.int/diagnostics_laboratory/publications/FR _HIVEval_Guide.pdf. Consulte le 1 janvier 2018

[11] J.J. Kwiek, V. Mwapasa, A.P. Alker, A.S. Muula, H.E. Misiri, M.E. Molyneux et al. Socio-demographic characteristics associated with HIV and syphilis seroreactivity among pregnant women in Blantyre, Malawi, 2000-2004. Malawi Medical J. 2008; 20(3):80-85.

[12] J.R. Hargreaves, J.R. Glynn. Trop Med Int Health. Educational attainment and HIV-1 infection in developing countries: a systematic review. 2002;7(6):489-98.

[13] B.C. Ukaire, C.O. Agboghoroma, K.W. Durojaiye. The Prevalence of Human Immunodeficiency Virus Infection among Pregnant Women in Labour with Unknown Status and those with Negative status early in the Index Pregnancy in a Tertiary Hospital in Nigeria. Afr J Reprod Health. 2015;19(3):137-143.

[14] C. Michelo, I.F. Sandoy, K. Fylkesnes. Marked HIV prevalence declines in higher educated young people: evidence from population-based surveys (1995-2003) in Zambia. AIDS. 2006;20:1031-1038.

[15] UNAIDS. Report on the Global HIV/AIDS Epidemic. Geneva: UNAIDS, 2011. 224p
[16] R. Mabala. From HIV prevention to HIV protection: addressing the vulnerability of girls and young women in urban areas. Sage J. 2006;18(2): 407-432.

[17] J.W. Eaton, T.M. Rehle, S. Jooste, R. Nkambule, A.A. Kim, M. Mahy, et al. Recent HIV prevalence trends among pregnant women and all women in sub-Saharan Africa: implications for HIV estimates. AIDS (London, England). 2014;28(4):S507-S514. doi:10.1097/QAD.0000000000000412.

[18] B. Varghese, J.E. Maher, T.A. Peterman et al. Reducing the Risk of Sexual HIV Transmission: Quantifying the Per-Act Risk for HIV on the Basis of Choice of Partner, Sex Act, and Condom Use. Sexually Transmitted Diseases. 2002;29(1):38-43.

[19] South African Department of Education. Monitoring and Evaluation Report on the Impact and Outcomes of the Education System on South Africa's Population: Evidence from Household Surveys. Pretoria: Department of Education, 2006. 88p

[20] E. Duflo, P. Dupas, M. Kremer, S. Sinei. Education and HIV/AIDS Prevention: evidence from a randomized evaluation in Western Kenya. World Bank Policy Research Working Paper. 2006. 33p

[21] A.E. Pettifor, B.A. Levandowski, C. MacPhail, N.S. Padian, M.S. Cohen, H.V. Rees. Keep them in school: the importance of education as a protective factor against HIV infection among young South African women. Inter of Epi. 2008;37:1266-1273. 